\title{
THỰC TRANG TUÂN THỦ VÊ SINH TAY CỦA ĐIỀU DƯỠNG TẠI BỆNH VIỆN THANH NHÀN GIAI ĐOẠN 2018-2019
}

\section{TÓM TẮT}

Nghiên cứu theo dõi dọc nhằm mô tả thực trạng tuân thủ về sinh tay của điều dưỡng tai Bểnh viện Thanh Nhàn năm 2018-2019. Nghiên cứu được thực hiên trên 190 điều dưỡng tại các khoa lâm sàng của bệnh viện Thanh Nhàn trong năm 2018 và 2019. Tổng cộng 11226 cơ hội vệ sinh tay được quan sát. Kết quả nghiên cứu cho thấy, tỷ lệ tuân thủ vệ sinh tay của điêu dưỡng tại Bênh viện Thanh Nhàn nói chung là 49,8\%, năm 2018 là 49,6\%, 2019 là 50,1\%. Khoa Răng hàm măt có tỷ lê tuân thủ vê sinh tay thấp nhất với $46,9 \%$, tiếp đến là Liên chuyên khoa $(47,2 \%)$ và Nhi $(47,3 \%)$. Tỳ lê tuân thủ về sinh tay cao nhất ở khoa Nội thận tiết niệu $(52,0 \%)$, Hồi sức tích cực $(52,1 \%)$ và Sản $(52,0 \%)$. Như vây, tỷ lê tuân thủ vệ sinh tay nói chung của điều dưỡng Bệnh viện Thanh Nhàn còn ở mức thấp. Các can thiệp giúp nâng cao tỷ lệ tuân thủ vệ sinh tay nói chung, vệ sinh tay sau khi tiếp xúc với người bệnh tại các khoa lâm sàng cân được xây dựng và triển khai trong tương lai.

Tư khóa: vệ sinh tay, nhiểm khuẩn bệnh viện, kiểm soát nhiễm khuẩn, điêuu dưỡng.

\section{SUMMARY}

HAND HYGIENE COMPLIANCE IN NURSES AT THANH NHAN HOSPITAL DURING 2019-2019

A longitudinal follow-up study to describe the status of hand hygiene compliance of nurses at Thanh Nhan Hospital in 2018-2019. The study was conducted on 190 nurses in clinical departments of Thanh Nhan hospital in 2018 and 2019. A total of 11226 hand hygiene opportunities were observed. Study results showed that the hand hygiene compliance rate of nurses at Thanh Nhan Hospital was $49.8 \%$, with $49.6 \%$ in 2018 and $50.1 \%$ in 2019. The Department of Odonto-Stomatology has the lowest hand hygiene compliance rate with $46.9 \%$, followed by Multispecialities Department (47.2\%) and Pediatrics Department $(47.3 \%)$. The rate of hand hygiene compliance was highest in the Departments of Urology $(52.0 \%)$, Intensive care Unit $(52.1 \%)$ and Obstetrics $(52.0 \%)$.In conclusion, the general hand hygiene compliance rate of nurses at Thanh Nhan Hospital was low. Interventions to help improve the compliance rate of hand hygiene in general, hand hygiene after

*Bênh viên Thanh Nhàn

**Trường Đại hoc Y Dược Hải Phòng

***Viên sức khỏe nghề nghiệp \& MT

Chịu trách nhiệm chính: Trân Thanh Tú

Email: tranthanhtu78bvtn@gmail.com

Ngày nhận bài: 16.8.2021

Ngày phản biên khoa họ: 18.10.2021

Ngày duyệt bài: 25.10 .2021
Trần Thanh Tú*, Phạm Minh Khuê**, Doãn Ngọc Hải***, Nguyển Thị Kim Dung*

contact with patients in clinical departments, need to be developed and implemented in the future.

Keywords: hand hygiene, hospital-acquired infection, infection control, nurse

\section{I. ĐẶT VẤN ĐỀ}

Nhiễm khuẩn bệnh viện (NKBV) hay nhiễm khuẩn liên quan đến chăm sóc sức khỏe là nhiễm khuẩn xảy ra tại các cơ sở y tế sau khi người bệnh nhập viện ít nhất 48 tiếng, mà không phải là ủ bệnh hoặc có triệu chứng tại thời điểm nhập viên [1]. NKBV bao gồm cả nhiếm khuẩn ở người bệnh đã xuất viện và nhiễm khuẩn nghề nghiệp ở NVYT [2, 3]. Kiểm soát nhiễm khuẩn (KSNK) là một trong những ưu tiên hàng đâu trong vận hành các cơ sở y tế, và là chỉ tiêu được sử dụng để đánh giá đảm bảo chất lượng bệnh viện. Các chương trình và quy định về KSNK cũng đã được ban hành ở các quốc gia, từ đó giúp làm giảm thiểu gánh nặng do NKBV gây ra cho cơ sở y tế và người bệnh. Trong đó, tăng cường tuân thủ các quy trình KSNK, đặc biệt là quy trình vệ sinh tay đóng vai trò trọng tâm của các chương trình can thiệp nâng cao khả năng KSNK tại các khoa và đơn vị của bệnh viện. TCYTTG ủng hộ rằng vệ sinh tay hiệu quả là thực hành quan trọng nhất để ngăn ngừa và kiểm soát NKBV và tình trạng vi khuẩn kháng kháng sinh [4].

Bệnh viện Thanh Nhàn là bệnh viện đa khoa hạng I của thành phố Hà Nội. Các báo cáo điêu tra tại bệnh viện cho thấy tỷ lệ mắc NKBV đang có xu hướng gia tăng. Điêuu này nảy sinh nhu câu tìm hiểu thực trạng KSNK tại bệnh viện, đặc biệt là tình trạng tuấn thủ quy trình vệ sinh tay của điều dưỡng. Do đó, nghiên cứu này được thực hiện nhằm: "Mô tả thực trạng tuân thủ vệ sinh tay của điều dưỡng tại Bệnh viện Thanh Nhàn năm 2018-2019". Kết quả nghiên cứu được kỳ vọng sẽ giúp các nhà quản lý y tế có những dữ liệu cân thiết để phát triển những biện pháp KSNK và đưa ra những khuyến cáo tốt hơn trong thực hành của điều dưỡng, góp phân làm giảm tî lệ NKBV khi điêuu trị và chăm sóc cho người bệnh.

\section{II. ĐỐI TƯỢNG VÀ PHƯƠNG PHÁP NGHIÊN CỨU}

2.1. Đối tượng nghiên cứu. Điêu dưỡng đang công tác tại các khoa Lâm sàng của bệnh viện Thanh Nhàn, là những người trực tiếp chăm sóc người bệnh. Tiêu chuẩn loại trừ bao gồm: 1) 
Những người đang đi học, nghỉ thai sản, ốm hoặc từ chối tham gia; 2) Nhứng điều dưỡng dị ứng với các loại hoá chất dùng trong vệ sinh tay.

\subsection{Thời gian và địa điểm nghiên cứu}

Nghiên cứu được tiến hành tại Bệnh viện Thanh Nhàn năm 2018 và 2019.

2.3. Thiết kế nghiên cứu. Nghiên cứu theo dõi dọc được tiến hành.

2.4. Cỡ mẫu và chọn mẫu: Tổng cộng 190 điều dưỡng được lựa chọn quan sát quy trình vệ sinh tay. Các điều dưỡng này sẽ được chọn ngẫu nhiên trong danh sách điều dưỡng của bệnh viện theo các bước sau:

- Bước 1: Lập danh sách khoa lâm sàng tại bệnh viện và danh sách điều dưỡng tại khoa

- Bước 2: Lựa chọn ngẫu nhiên đớn 190 điều dưỡng theo danh sách vừa lập. Nếu có điều dưỡng không đồng ý tham gia nghiên cứu, điều dưỡng tiếp theo trong danh sách sẽ được lựa chọn.

Số cơ hội vệ sinh tay cần quan sát: Mỗi điều dưỡng sẽ được đánh giá ít nhất 1 lần/năm, mỗi lần 5 cơ hội vệ sinh tay bao gồm:

- Trước khi tiếp xúc người bênh

- Trước khi làm thủ thuật hoặc quy trình sạch/vô khuẩn

- Sau khi có nguy cơ tiếp xúc dịch cơ thể

- Sau khi tiếp xúc người bệnh

- Sau khi tiếp xúc bề mă̆t xung quanh người bệnh

Quan sát được thực hiện ngẫu nhiên các thời điểm vào các ngày trong tuần. Thực tế năm 2018, nghiên cứu đã quan sát được 5463 cơ hội, năm 2019 nghiên cứu đã quan sát 5763 cơ hội.

2.5. Cách thức thu thập thông tin về tuân thủ quy trình vệ sinh tay. Được thực hiện bằng phương pháp quan sát không tham gia có sử dụng bảng kiểm được xây dựng sẵn dựa trên bộ công cụ đánh giá tuân thủ rửa tay đã được chuẩn hóa của Tố chức $Y$ tế thễ giới. Quan sát viên sử dụng bộ công cụ và cách đánh giá sự tuân thủ rửa tay, chọn vị trí quan sát không gây sự chú ý của điêu dưỡng và quan sát đối tượng thực hiện những thao tác chăm sóc, điều trị người bệnh tại phòng bệnh hoặc giường bệnh, thời gian của mối lần quan sát từ 20-30 phút nhằm đảm bảo quan sát được ít nhất 2-3 cơ hội điều dưỡng cần rửa tay hoặc sát khuẩn tay. Quy trình vệ sinh tay chỉ được ghi nhận khi điều dưỡng thực hiện trong buồng bệnh. Tuân thủ vệ sinh tay được ghi nhận khi điêu dưỡng hoàn thành đúng quy trình 6 bước. Trong quá trình thu thập số liệu, nghiên cứu viên thực hiện việc giám sát để đảm bảo chất lượng của số liệu thu thập được và tránh những sai số do quá trình thu thập số liệu.

2.6. Phẩn tích số liệu. Số liệu được nhập vào phần mềm Epidata, phân tích bằng phần mềm Stata 15.0. Kết quả phân tích được biểu diễn bằng tần số và tỷ lệ $\%$. Test kiểm định $x 2$ được sử dụng để so sánh tỷ lệ tuân thủ vệ sinh tay giữa các khoa.

2.7. Đạo đức nghiên cứu: Nghiên cứu đã được Hội đồng Đạo đức Bệnh viện Thanh Nhàn thông qua

\section{KẾT QUẢ NGHIÊN CỨU}

Trong nghiên cứu, có tổng cộng 6 cơ hội rửa tay cho điều dưỡng, được phân hai thời điểm:

- Trước khi tiếp xúc với người bệnh (bao gồm giai đoạn trước khi tiếp xúc với người bệnh, trước khi thực hiện thủ thuật hoặc quy trình sạch, vô khuẩn, đi găng sạch).

- Sau khi tiếp xúc với người bệnh (bao gồm sau khi khám/chăm sóc cho người bệnh, sau khi tiếp xúc dịch cơ thể, sau khi làm thủ thuật, sau khi tiếp xúc môi trường xung quanh người bệnh)

3.1. Trước khi tiếp xúc với người bệnh. Bảng 1 cho thấy, với tổng cộng 4552 lần quan sát trong năm 2018, tỷ lệ tuân thủ vệ sinh tay trước khi tiếp xúc với người bệnh nói chung là $47,4 \%$. Tỷ lệ này tăng lên 47,7\% (trong 4802 lần quan sát) năm 2019. Nhìn chung, trước can thiệp, tỷ lệ tuân thủ vệ sinh tay là $47,6 \%$. Sự khác biệt về tỷ lệ này giữa hai năm không có ý nghĩa với $p>0,05$. tỷ lệ tuân thủ về sinh tay cao nhất ở khoa Khám bệnh $(49,6 \%)$, khoa Sản $(49,3 \%)$, và Khoa Hồi sức tích cực $(49,1 \%)$. Thấp nhất là các khoa Ngoại tổng hợp (45,2\%). Tỷ lệ tuân thủ vệ sinh tay nhìn chung có sự tăng lên qua thời gian ở các khoa, tuy nhiên mức độ tăng lên không đáng kể.

Bảng 1. Tuân thủ quy trình vệ sinh tay trước khi tiếp xúc người bệh theo khoa

\begin{tabular}{|c|c|c|c|c|c|c|c|c|c|}
\hline \multirow[b]{2}{*}{ Khoa } & \multicolumn{3}{|c|}{2018} & \multicolumn{3}{|c|}{2019} & \multicolumn{3}{|c|}{ Tống } \\
\hline & $\begin{array}{c}\text { Số lần } \\
\text { quaan } \\
\text { sát }\end{array}$ & $\begin{array}{c}\text { Số lần } \\
\text { tuân } \\
\text { thủ }\end{array}$ & $\%$ & $\begin{array}{c}\text { Số lân } \\
\text { quan sát }\end{array}$ & $\begin{array}{c}\text { Số lần } \\
\text { tuân } \\
\text { thủ }\end{array}$ & $\%$ & $\begin{array}{c}\text { Số lần } \\
\text { quaan } \\
\text { sát }\end{array}$ & $\begin{array}{c}\text { Số lần } \\
\text { tuân } \\
\text { thủ }\end{array}$ & $\%$ \\
\hline & 181 & 88 & & & 96 & & 377 & 184 & 48,8 \\
\hline & 178 & 8. & 46,6 & & 88 & 46,8 & 366 & 171 & 46 \\
\hline Chuyên kho & 1417 & 672 & 47,4 & 1477 & 702 & 47,5 & 2894 & 1374 & 47,5 \\
\hline Ngoại thận tiết niệu & 164 & 78 & 47,6 & 174 & 83 & 47,7 & 338 & 161 & 47,6 \\
\hline
\end{tabular}


VIETNAM MEDICAL JOURNAL N² - NOVEMBER - 2021

\begin{tabular}{|c|c|c|c|c|c|c|c|c|c|}
\hline Ngoại tống hợp & 336 & 151 & 44,9 & 361 & 164 & 45,4 & 697 & 315 & 45,2 \\
\hline Chuyên khoa Ngoại khác & 495 & 229 & 46,3 & 535 & 249 & 46,5 & 1030 & 478 & 46,4 \\
\hline Cấp cứu & 374 & 178 & 47,6 & 389 & 187 & 48,1 & 763 & 365 & 47,8 \\
\hline Hồi sức tích cực & 407 & 199 & 48,9 & 432 & 213 & 49,3 & 839 & 412 & 49,1 \\
\hline Sản & 362 & 178 & 49,2 & 382 & 189 & 49,5 & 744 & 367 & 49,3 \\
\hline Nhi & 164 & 78 & 47,6 & 174 & 83 & 47,7 & 338 & 161 & 47,6 \\
\hline Liên chuyên khoa & 143 & 66 & 46,2 & 148 & 69 & 46,6 & 291 & 135 & 46,4 \\
\hline Răng hàm mặt & 143 & 66 & 46,2 & 153 & 72 & 47,1 & 296 & 138 & 46,6 \\
\hline Khoa khám bệnh & 188 & 93 & 49,5 & 193 & 96 & 49,7 & 381 & 189 & 49,6 \\
\hline Tống & $\mathbf{4 5 5 2}$ & $\mathbf{2 1 5 9}$ & $\mathbf{4 7 , 4}$ & $\mathbf{4 8 0 2}$ & $\mathbf{2 2 9 1}$ & $\mathbf{4 7 , 7}$ & $\mathbf{9 3 5 4}$ & $\mathbf{4 4 5 0}$ & $\mathbf{4 7 , 6}$ \\
\hline
\end{tabular}

3.2. Sau khi tiếp xúc với người bệnh. Bảng 2 cho thấy, với tổng cộng 911 lần quan sát trong năm 2018, tỷ lệ tuân thủ vệ sinh tay sau khi tiếp xúc với người bệnh là $60,1 \%$. Tỷ lệ này tăng lên $61,8 \%$ (trong 961 lần quan sát) năm 2019. Nhìn chung, tỷ lệ tuân thủ vệ sinh tay nói chung là $61,0 \%$. Sự khác biệt về tỷ lệ này giữa hai năm không có ý nghĩa với $p>0,05$. Tỷ lệ tuân thủ vệ sinh tay cao nhất ở các khoa Nội thận tiết niệu $(68,0 \%)$, Hồi sức tích cực $(67,3 \%)$ và Sản $(65,5 \%)$. Tỷ lệ tuân thủ vệ sinh tay thấp nhất ở khoa Nhi $(45,6 \%)$.

Bảng 2. Tuân thủ quy trình vệ sinh tay sau khi tiêp xúc người bệnh theo khoa

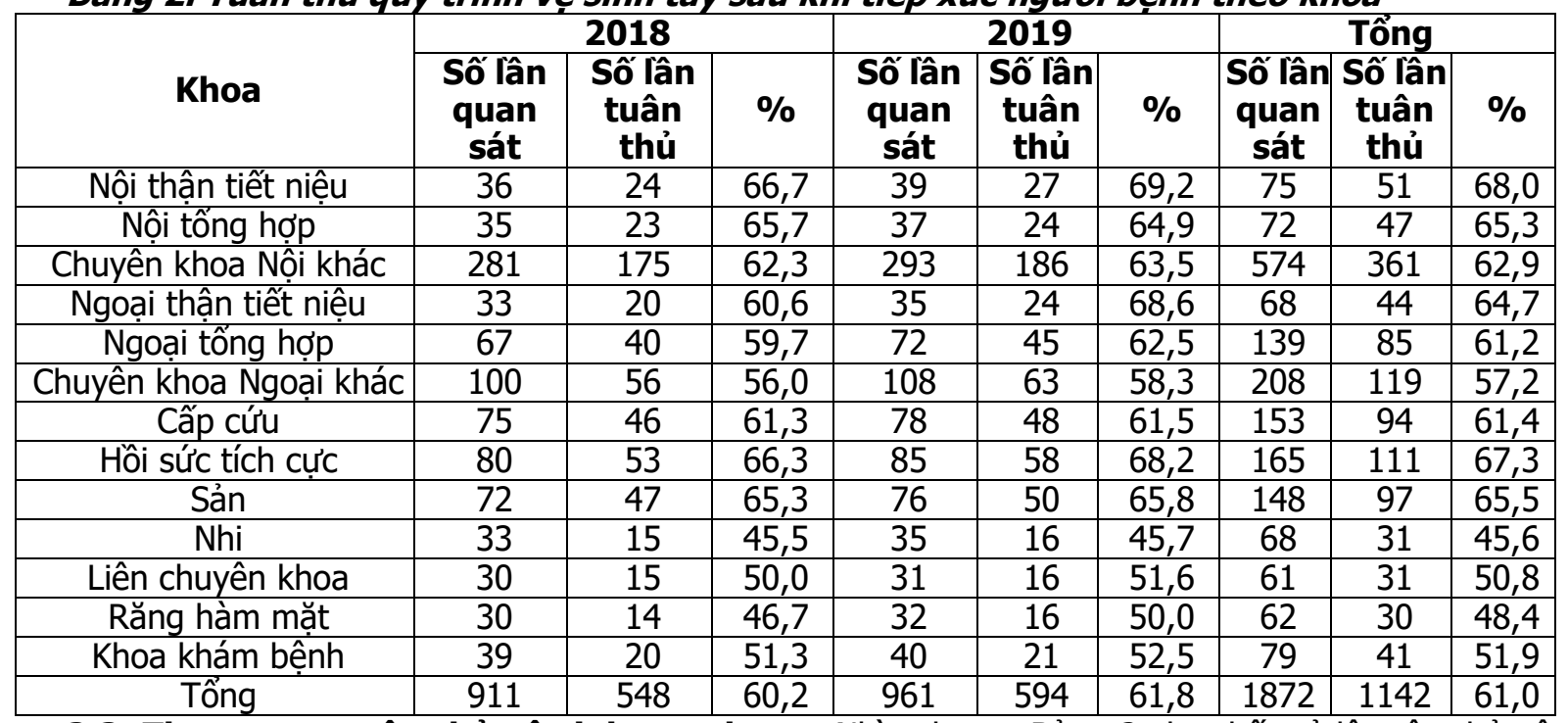

3.3. Thực trạng tuân thủ vệ sinh tay chung. Nhìn chung, Bảng 3 cho thấy tỷ lệ tuân thủ vệ sinh tay của điều dưỡng tại Bệnh viện Thanh Nhàn nói chung là 49,8\%, năm 2018 là 49,6\%, 2019 là $50,1 \%$. Khoa Răng hàm mặt có tỷ lệ tuân thủ vệ sinh tay thấp nhất với $46,9 \%$, tiếp đến là Liên chuyên khoa $(47,2 \%)$ và Nhi $(47,3 \%)$. Tỷ lệ tuân thủ vệ sinh tay cao nhất ở khoa Nội thận tiết niệu $(52,0 \%)$, Hồi sức tích cực $(52,1 \%)$ và Sản $(52,0 \%)$.

Bảng 3. Tuân thủ quy trinh vệ sinh tay nói chung theo khoa

\begin{tabular}{|c|c|c|c|c|c|c|c|c|c|}
\hline \multirow[b]{2}{*}{ Khoa } & \multicolumn{3}{|c|}{2018} & \multicolumn{3}{|c|}{2019} & \multicolumn{3}{|c|}{ Tống } \\
\hline & $\begin{array}{c}\text { Số } \\
\text { lấn } \\
\text { quaan } \\
\text { sát }\end{array}$ & $\begin{array}{c}\text { Số } \\
\text { lân } \\
\text { tuân } \\
\text { thủ }\end{array}$ & $\%$ & $\begin{array}{c}\text { Số } \\
\text { lânn } \\
\text { quaan } \\
\text { sát }\end{array}$ & $\begin{array}{c}\text { Số } \\
\text { lân } \\
\text { tuân } \\
\text { thủ }\end{array}$ & $\%$ & $\begin{array}{l}\text { Số lân } \\
\text { quan } \\
\text { sát }\end{array}$ & $\begin{array}{l}\text { Số' } \\
\text { lân } \\
\text { tuân } \\
\text { thủ }\end{array}$ & $\%$ \\
\hline Nội thận tiết niệu & 217 & 112 & 51,6 & 235 & 123 & 52,3 & 452 & 235 & 52,0 \\
\hline Nội tống hợp & 213 & 106 & 49,8 & 225 & 112 & 49,8 & 438 & 218 & 49,8 \\
\hline Chuyên khoa Nội khác & 1698 & 847 & 49,9 & 1770 & 888 & 50,2 & 3468 & 1735 & 50,0 \\
\hline Ngoại thận tiết niệu & 197 & 98 & 49,7 & 209 & 107 & 51,2 & 406 & 205 & 50,5 \\
\hline Ngoại tổng hợp & 403 & 191 & 47,4 & 433 & 209 & 48,3 & 836 & 400 & 47,8 \\
\hline Chuyên khoa Ngoại khác & 595 & 285 & 47,9 & 643 & 312 & 48,5 & 1238 & 597 & 48,2 \\
\hline Cấp cứu & 449 & 224 & 49,9 & 467 & 235 & 50,3 & 916 & 459 & 50,1 \\
\hline Hồi sức tích cực & 487 & 252 & 51,7 & 517 & 271 & 52,4 & 1004 & 523 & 52,1 \\
\hline
\end{tabular}




\begin{tabular}{|c|c|c|c|c|c|c|c|c|c|}
\hline Sản & 434 & 225 & 51,8 & 458 & 239 & 52,2 & 892 & 464 & 52,0 \\
\hline Nhi & 197 & 93 & 47,2 & 209 & 99 & 47,4 & 406 & 192 & 47,3 \\
\hline Liên chuyên khoa & 173 & 81 & 46,8 & 179 & 85 & 47,5 & 352 & 166 & 47,2 \\
\hline Răng hàm mặt & 173 & 80 & 46,2 & 185 & 88 & 47,6 & 358 & 168 & 46,9 \\
\hline Khoa khám bệnh & 227 & 113 & 49,8 & 233 & 117 & 50,2 & 460 & 230 & 50,0 \\
\hline Tống & $\mathbf{5 4 6 3}$ & $\mathbf{2 7 0 7}$ & $\mathbf{4 9 , 6}$ & $\mathbf{5 7 6 3}$ & $\mathbf{2 8 8 5}$ & $\mathbf{5 0 , 1}$ & $\mathbf{1 1 2 2 6}$ & $\mathbf{5 5 9 2}$ & $\mathbf{4 9 , 8}$ \\
\hline
\end{tabular}

Biểu đồ 1 cho thấy, so với trước khi tiếp xúc với người bệnh, tỷ lệ tuân thủ vệ sinh tay sau khi tiếp xúc với người bệnh tăng một cách đáng kể ở hầu hết các khoa (trừ khoa Nhi).

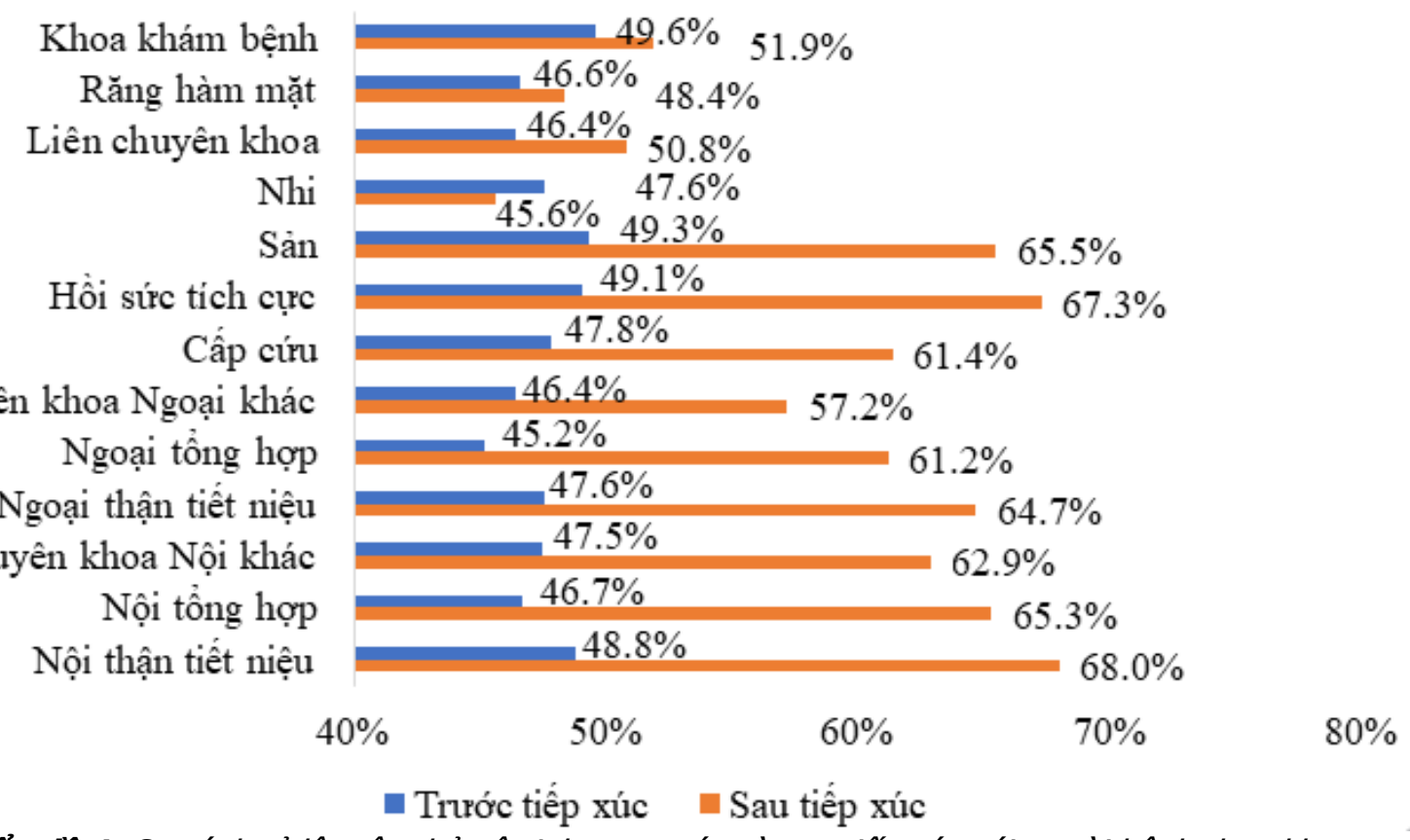

Biểu đồ 1. So sánh tỷ lệ tuân thủ vệ sinh tay trước và sau tiếp xúc với người bệnh theo khoa

\section{BÀN LUÂ̂N}

Kết quả nghiên cứu cho thấy, tỷ lệ tuân thủ vệ sinh tay của điều dưỡng tại Bệnh viện Thanh Nhàn nói chung là $49,8 \%$. Qua quan sát, quá trình thực hiện vệ sinh tay của điều dưỡng vẫn còn thiếu xót. Trên thực tế, mặc dù các quy định và hướng dẫn rửa tay theo quy định của Bộ Y tế được dán phổ biến tại bệnh viện, điều dưỡng tham gia nghiên cứu thường không rửa tay đúng trình tự hoặc bỏ bước trong 6 bước quy định. Điều này cho thấy cần có các biện pháp nhắc nhở khác để cho điều dưỡng đảm bảo tuân thủ quy trình vệ sinh tay.

Trong nghiên cứu này, có tổng cộng 6 cơ hội rửa tay cho điều dưỡng, được phân làm hai thời điểm: trước khi tiếp xúc với người bệnh (bao gồm giai đoạn trước khi tiếp xúc với người bệnh, trước khi thức hiện thủ thuật hoặc quy trình sạch, vô khuẩn, đi găng sạch) và sau khi tiếp xúc với người bệnh (bao gồm sau khi khám/chăm sóc cho người bệnh, sau khi tiếp xúc dịch cơ thể, sau khi làm thủ thuật, sau khi tiếp xúc môi trường xung quanh người bệnh). Nghiên cứu bám theo chiến lược " 5 Thời điểm Vệ sinh Bàn tay của Tôi" (My 5 moments for Hand Hygiene) của TCYTTG nhằm xác định khi nào NVYT nên thực hiện vệ sinh tay trong quá trình chăm sóc lâm sàng [4]. Tuy nhiên, tỷ lệ tuân thủ vệ sinh tay trước tiếp xúc người bệnh đạt dưới $50 \%$ và tỷ lê đat sau tiếp xúc với người bênh đạt trên $60 \%$, cho thấy khoảng trống về tuân thủ vệ sinh tay ở điều dưỡng của bệnh viện.

Kết quả nghiên cứu này tương đương với một số nghiên cứu khác. Võ Văn Tân và cộng sự (2010) nghiên cứu về hành vi của 200 điều dưỡng về kiểm soát nhiễm khuẩn bệnh viện tại Bệnh viện Tiền Giang. Kết quả nghiên cứu cho thấy, chỉ có $56,7 \%$ tuân thủ rửa tay, $5 \%$ thực hiện đúng quy trình rửa tay thường quy [5]. Điểu tra của Nguyễn Nam Thắng và Lê Đức Cường đánh giá thực hành rửa tay thường quy cho thấy, tỷ lệ điều dưỡng viên thực hành rửa tay thường quy Đạt ở cả hai bệnh viện rất thấp, ơ bệnh viện đa khoa huyện Tiển Hải là 45,0\% và ở 
bệnh viện đa khoa Nam Tiền Hải là $25,8 \%$ $(p<0,05)$ [7]. Phạm Hữu Khang và cộng sự (2016) nghiên cứu trên 6850 lần thực hành của nhân viên y tế tại bệnh viện An Bình. Kết quả cho thấy, tỷ lệ tuân thủ vệ sinh tay là $42,88 \%$. Có sự khác nhau giữa 5 thời điểm bắt buộc rửa tay: tuân thủ rửa tay cao nhất là sau khi tiếp xúc với máu $(75,5 \%)$, trước thực hiên các thủ thuâtt vô khuẩn $(67,18 \%)$ và thấp nhất là trước tiếp xúc với người bệnh (22,83\%), sau khi chạm vào những vùng xung quanh người bệnh $(24,48 \%)$. Các khoa có sự tuân thủ rửa tay cao là Nhiễm $(61,46 \%)$, Hồi sức tích cực $(54,04 \%)$. Điều dưỡng, kỹ thuật viên, nữ hổ sinh tuân thủ rửa tay cao nhất $(44,8 \%)$, thấp nhất là bác sỹ $(30,33 \%)$. Rửa tay bằng dung dịch chứa cồn có sự lựa chọn nhiều hơn $(54,24 \%)$ so với nước và xà phòng $(45,76 \%)[8]$.

Đáng chú ý, tỷ lệ tuân thủ vệ sinh tay trước tiếp xúc với người bệnh thấp hơn đáng kể so với sau khi tiếp xúc với người bệnh. Thực tế cho thấy, trước khi chuẩn bị chăm sóc người bệnh, điều dưỡng thường rửa tay và sau đó sẽ cham vào 1 vật nào đó trong buồng bệnh (có thể là chạm vào áo blouse, chạm vào bệnh án, chạm vào đồ dùng của bệnh nhân hoặc bề mặt ngoài của các dụng cụ y tế ...) do đó, bàn tay họ lại bị nhiễm vi khuẩn và có thể là loại vi khuẩn đa kháng kháng sinh. Do đó, đối với người bệnh, việc điều dưỡng rửa tay trước khi chăm sóc người bệnh cần được nhấn mạnh trong các can thiệp cải thiện tuân thủ vệ sinh tay.

Khi đánh giá theo khoa, Khoa Răng hàm mă̆t có tỷ lệ tuân thủ vệ sinh tay thấp nhất với $46,9 \%$, tiếp đến là Liên chuyên khoa $(47,2 \%)$ và Nhi (47,3\%). Tỷ lệ tuân thủ vệ sinh tay cao nhất ở khoa Nội thận tiết niệu $(52,0 \%)$, Hồi sức tích cực $(52,1 \%)$ và Sản $(52,0 \%)$. Sự khác biệt này có thể do tình trạng trang bị dung dịch sát khuẩn tay nhanh cho từng khoa còn khác biệt. Theo thói quen, điều dưỡng sau khi chăm sóc người bệnh thường rửa tay bằng nước và xà phòng tại bồn rửa tay được bố trí ngoài phòng khám hoặc sát khuẩn tay với cồn $70^{\circ}$ có sẵn trên bàn hoặc trên xe tiêm. Việc không bố trí đầy đủ trang thiết bị rửa tay có thể gây bất tiện cho điều dưỡng viên và họ thường lựa chọn sát khuẩn tay bằng dung dịch sát khuẩn. Điều này có thể gây khô da tay, tróc da, từ đó hình thành tâm lý ngại rửa tay hoặc để sau khi hoàn thành các công đoạn chăm sóc sẽ ra ngoài buồng bệnh để rửa tay. Đây cũng là điều cần lưu ý khi tiến hành can thiệp tăng cường tuân thủ vệ sinh tay tại các khoa phòng ở bệnh viện.
Nghiên cứu có một số hạn chế. Nghiên cứu chỉ giới hạn trong việc tìm hiểu tuân thủ vệ sinh tay mà không nghiên cứu sâu về kỹ thuật, thời gian, hiệu quả khử khuẩn tay của các hoá chất sử dụng vệ sinh tay. Ngoài ra, nghiên cứu chỉ tiến hành trên 1 bệnh viện, do đó kết quả có thế không phản ánh tình trạng tuân thủ vệ sinh tay của điều dưỡng ở các bệnh viện khác. Nghiên cứu cũng giới hạn tìm hiểu tình trạng tuân thủ vệ sinh tay của điều dưỡng, chưa có sự mở rộng ra các đối tượng khác. Đây là các hạn chế cần được khắc phục trong các nghiên cứu tiếp theo.

\section{KẾT LUÂ̂N}

Tỷ lệ tuân thủ vệ sinh tay nói chung của điều dưỡng Bệnh viện Thanh Nhàn còn ở mức thấp. Các can thiệp giúp nâng cao tỷ lệ tuân thủ vệ sinh tay nói chung, vệ sinh tay sau khi tiếp xúc với người bệnh tại các khoa lâm sàng, đặc biệt là khoa Ngoại thận tiết niệu cần được xây dựng và triển khai trong tương lai.

\section{TÀI LIẸU THAM KHẢO}

1. Bộ Y tế (2012), Quyết định số 3671/QĐ-BYT ngày 27 thang 9 năm 2012 của Bộ trưởng Bộ $Y$ tế phê duyệt các hướng dẩn kiểm soát nhiểm khuẩn, chủ biên.

2. J. S. Garner, W. R. Jarvis, T. G. Emori và các cộng sự. (1988), "CDC definitions for nosocomial infections, 1988", Am J Infect Control, 16(3), tr. $128-40$.

3. T. C. Horan, R. P. Gaynes, W. J. Martone và các cộng sứ. (1992), "CDC definitions of nosocomial surgical site infections, 1992: a modification of CDC definitions of surgical wound infections", Infect Control Hosp Epidemiol, 13(10), tr. 606-8.

4. World Health Organization (2009), WHO Guidelines on Hand Hygiene in Health Care: First Global Patient Safety Challenge Clean Care Is Safer Care, World Health Organization Copyright (c) 2009, World Health Organization., Geneva.

5. Võ Văn Tân, Lê Thị Anh Thư và Nancy White (2010), "Liên quạn giữa kiến thức và hành vi của điêu dưỡng về kiểm soát nhiếm trùng bệnh viện", Tạp chí Y học thành phố Hồ Chí Minh, 14(4).

6. Nguyễn Thanh Loan, Lora Claywell và Trân Thiện Trung (2014), "Kiến thức và thực hành của điều dưỡng về phòng ngửa nhiểm trùng vết mổ", Tap chí Y họ thành phố Hồ Chí Minh, 18(5) tr. 129-135.

7. Nguyên Nam Thắng và Lê Đức Cường (2017), "Thực hành rửa tay thường quy của điều dưỡng viên tại hai bệnh viện đa khoa huyện Tiền Hải, Thái Bình và một số yếu tố liên quan", Tạp chí y học dự phòng, 27(6), tr. 230.

8. Phạm Hữu Khang, Nguyển Thị Kim Yến, Lê Ngọc Thái Hòa và các cộng sự. (2016), "Tỷ lệ tuân thủ về sinh tay của nhân viên y tê tai các khoa lâm sảng bệnh viện An Bình", Tạp chí Y học thành phố Hồ Chí Minh, 20(5). 